\title{
Altered postprandial hormone and metabolic responses in a simulated shift work environment
}

\author{
D C O Ribeiro, S M Hampton, L Morgan, S Deacon and \\ J Arendt
}

School of Biological Sciences, University of Surrey, Guildford, Surrey GU2 5XH, UK

(Requests for offprints should be addressed to D Ribeiro)

\begin{abstract}
The circadian rhythms of most night shift workers do not adapt fully to the imposed behavioural schedule, and this factor is considered to be responsible for many of the reported health problems. One way in which such disturbances might be mediated is through inappropriate hormonal and metabolic responses to meals, on the night shift.

Twelve healthy subjects (four males and eight females) were studied on three occasions at the same clock time (1330 h), but at different body clock times, after consuming test meals, first in their normal environment, secondly after a forced $9 \mathrm{~h}$ phase advance (body clock time approximately $2230 \mathrm{~h}$ ) and then again 2 days later in the normal environment. They were given a low-fat pre-meal at $0800 \mathrm{~h}$, then a test meal at $1330 \mathrm{~h}$ with blood sampling for the following $9 \mathrm{~h}$. Parameters measured included plasma glucose, non-esterified fatty acids (NEFAs), triacylglycerol (TAG), insulin, C-peptide, proinsulin and glucose-
\end{abstract}

dependent insulinotropic polypeptide, and urinary 6-sulphatoxymelatonin.

In contrast with a previous study with a high-fat premeal, postprandial glucose and insulin responses were not affected by the phase shift. However, basal plasma NEFAs were lower immediately after the phase shift $(P<0 \cdot 05)$. Incremental (difference from basal) TAG responses were significantly higher $(P<0 \cdot 05)$ immediately after the phase shift compared with before. Two-day post-phase shift responses showed partial reversion to baseline values.

This study suggests that it takes at least 2 days to adapt to eating meals on a simulated night shift, and that the nutritional content of the pre-meals consumed can have a marked effect on postprandial responses during a simulated phase shift. Such findings may provide a partial explanation for the increased occurrence of cardiovascular disease reported in shift workers.

Journal of Endocrinology (1998) 158, 305-310

\section{Introduction}

With the ever increasing demand for 'round the clock' services, shift work is becoming considerably more commonplace. Aside from the decrease in work performance and efficiency (Monk et al. 1996) and the social problems encountered (Smith \& Folkard 1993, Chan 1994), shift workers are also susceptible to a deterioration in health. Short-term problems include disturbances in sleeping and eating habits, whilst longer-term more serious disorders involving gastrointestinal, neuropsychological and cardiovascular functions may develop (Costa 1996). Many workers have described the increased risk of cardiovascular disease to which night shift workers might be exposed (Akerstedt et al. 1984, Tuchsen 1993, Ekstrand et al. 1996). It has been estimated that between 20 and $50 \%$ of all workers have to stop participating in shift work within a very short time because of health problems (Costa 1996). One way in which such problems might be mediated is through inappropriate hormonal and metabolic responses to meals in unadapted night workers (Lennernas et al. 1994). In a recently published study conducted in our laboratory (Hampton et al. 1996), nine healthy subjects underwent test meal studies at the same clock time, first in their normal environment (body clock time of $1330 \mathrm{~h}$ ), and then immediately after a forced $9 \mathrm{~h}$ phase advance (body clock time of approximately $2230 \mathrm{~h}$ ). The gradual $9 \mathrm{~h}$ phase advance was induced using a previously reported procedure involving timed bright light and darkness (Deacon et al. 1996, Deacon \& Arendt 1996). Postprandial glucose and insulin responses were significantly higher at the same clock time after the phase shift than before it, and there was also an effect on circulating lipid levels, in that postprandial rises in plasma triacylglycerol (TAG) and non-esterified fatty acids (NEFAs) were delayed after the phase shift compared with before it.

The aim of this study was to extend the observations from our previous work (Hampton et al. 1996) on postprandial hormone and metabolic responses during simulated shift work. This was accomplished by increasing the 
number of subjects taking part in the study and extending the sampling period from 6 to $9 \mathrm{~h}$ so that longer-term effects could be investigated. In addition, a third test meal study was included, 2 days after the rapid 9 h phase delay, so that the speed of adaptation of any phase shift-related effects to the baseline conditions could be established. The pre-meal was modified to contain lower levels of fat, in an effort to remove the possibility of a masking effect of the high-fat pre-meal on the postprandial TAG responses in our initial study. Aside from these differences, the experimental procedure, including the content of the test meal, was exactly the same as described in our previous work (Hampton et al. 1996).

\section{Materials and Methods}

\section{Subjects}

Before commencement, ethical approval for the study was obtained from the University of Surrey Advisory Committee on Ethics, functioning according to the guidelines issued by the Royal College of Physicians of London in September 1984, and amended in November 1984 and August 1986. Twelve healthy subjects (four males and eight females), aged 19-27 years (mean \pm S.E.M. $24 \cdot 1 \pm 0.58$ years; median $24 \cdot 0$ years) with body mass indices of $20 \cdot 9-29 \cdot 0 \mathrm{~kg} / \mathrm{m}^{2}$ (mean \pm S.E.M. $24 \cdot 5 \pm$ $0.87 \mathrm{~kg} / \mathrm{m}^{2}$; median $22.6 \mathrm{~kg} / \mathrm{m}^{2}$ ), were recruited from the students and staff at the University of Surrey. Consent was obtained from each subject after full explanation of the purpose and nature of all procedures used. Subjects were all non-smokers and were taking no medication except for oral contraceptives and/or mild analgesics. Standard biochemistry and haematology screening was conducted before inclusion in the study, and written consent and doctor's approval were obtained. Throughout the study, subjects avoided strenuous exercise and exposure to bright natural light. During the periods of imposed darkness, all windows were blacked out. Subjects were instructed to consume no more than two units of alcohol per day, and no alcohol or caffeine were permitted during the $12 \mathrm{~h}$ before each test meal.

\section{Phase-shifting protocol}

Simulated phase shift was accomplished using a previously described method (Deacon et al. 1996, Deacon \& Arendt 1996, Hampton et al. 1996, Arendt et al. 1997). The protocol is outlined diagrammatically in Fig. 1, and summarised briefly here.

Baseline: for 4 days (D -3 to $\mathrm{D} 0$ ), subjects maintained a regular sleep/wake cycle, retiring to bed at $2330 \mathrm{~h}$, and rising at $0730 \mathrm{~h}$.

Gradual advance phase shift: after the baseline days, subjects were exposed to the following periods of bright full-spectrum light (Vitalite $1200 \mathrm{~lx}$, in the Clinical Investigation Unit, University of Surrey):

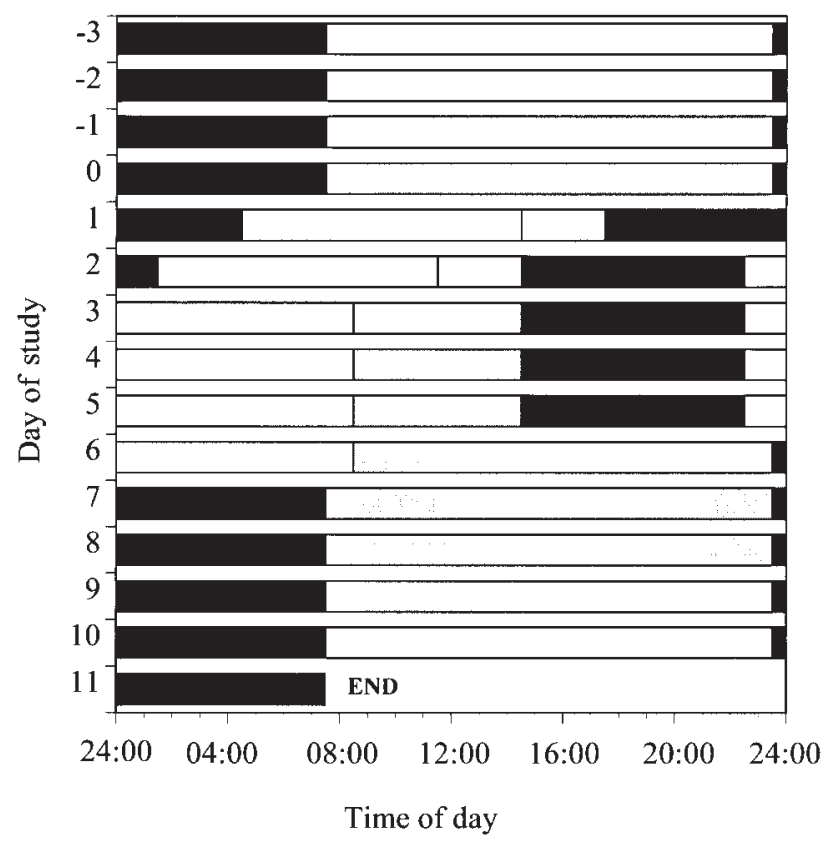

Figure 1 Diagrammatic representation of the phase-shifting protocol, illustrating the timing of exposure to bright light (1200 Ix; open bar), darkness/sleep (solid bar) and natural ambient light $(<300 \mathrm{~lx}$; shaded bar). After a 4-day baseline period ( $\mathrm{D}-3$ to D0), 12 volunteers were subjected to a gradual $9 \mathrm{~h}$ phase-advance shift (D1 to D3), which was reinforced for a further 2-day period (D4 to D5), and then resumed baseline conditions (i.e. a rapid $9 \mathrm{~h}$ phase-delay shift on D6). Three test meal studies were conducted: before the phase shift (D0), immediately after the phase shift (D6) and 2 days after the phase shift (D8).

$0430 \mathrm{~h}$ (D1) to $1430 \mathrm{~h}(\mathrm{D} 1)$

$0130 \mathrm{~h}(\mathrm{D} 2)$ to $1130 \mathrm{~h}(\mathrm{D} 2)$

$2230 \mathrm{~h}$ (D2) to $0830 \mathrm{~h} \mathrm{(D3)}$

$2230 \mathrm{~h} \mathrm{(D3)}$ to $0830 \mathrm{~h}(\mathrm{D} 4)$

$2230 \mathrm{~h} \mathrm{(D4)} \mathrm{to} 0830 \mathrm{~h} \mathrm{(D5)}$

$2230 \mathrm{~h} \mathrm{(D5)}$ to $0830 \mathrm{~h} \mathrm{(D6)}$

Each light treatment period was preceded by $8 \mathrm{~h}$ of imposed darkness. Mealtimes were shifted in parallel with the light/darkness cycle. During the remainder of each day, subjects could continue their normal activities indoors (light $<300 \mathrm{~lx}$ ) or outdoors wearing sunglasses (reducing light intensity by $>90 \%)$. Immediately after the last bright light treatment, subjects were required to resume baseline conditions, i.e. darkness between $2330 \mathrm{~h}$ and $0730 \mathrm{~h}$, for 6 days (D6-D11), and to wear sunglasses when outdoors, effectively undergoing an abrupt $9 \mathrm{~h}$ delay.

The phase shift was monitored using the circadian rhythm marker, urinary 6-sulphatoxymelatonin (aMT6 s). Urine was collected every $3-4 \mathrm{~h}$ (every $8 \mathrm{~h}$ when the subjects were asleep) for measurement of the major melatonin metabolite, aMT6 s; the volume was recorded and aliquots were frozen at $-20{ }^{\circ} \mathrm{C}$ until assayed. 
Test meal studies

Subjects were studied on D0, D6 and D8 (i.e. during the baseline period, immediately after a gradual $9 \mathrm{~h}$ phase advance, and 2 days after return to normal environment). At $0800 \mathrm{~h}$ on each of the study days, subjects were given a set pre-meal $(2008 \mathrm{~kJ}, 3 \cdot 4 \%$ fat, 92\% carbohydrate and $7 \cdot 8 \%$ protein). Subjects then refrained from eating or drinking until the test meal, apart from water which was freely available throughout the entire study. At $1330 \mathrm{~h}$, subjects were given a test meal comprising $3330 \mathrm{~kJ}, 37 \%$ fat, $52 \%$ carbohydrate and $11 \%$ protein. The meal was consumed within a $15 \mathrm{~min}$ period. Before the test meal, subjects were cannulated into an antecubital vein, and two baseline samples of $18 \mathrm{ml}$ were taken $(-10$ and $0 \mathrm{~min}$ ). Blood samples of $13 \mathrm{ml}$ were then taken for $9 \mathrm{~h}$ after the test meal (20, 40, 60, 90, 120, 180, 240, 300, 360, 420, 480 and $540 \mathrm{~min}$ ). Plasma was separated immediately by centrifugation, aliquoted and stored at $-20{ }^{\circ} \mathrm{C}$.

\section{Assay procedures}

Plasma glucose and TAG (both from Roche Products Ltd, Welwyn Garden City, UK) and NEFAs (Wako Chemicals, Neuss, Germany) were measured by standard automated enzymic spectrophotometric methods. The interassay coefficients of variation were less than $5 \%$ for these assays. Plasma immunoreactive insulin (Hampton \& Withey 1993), proinsulin (Hampton et al. 1988), C-peptide (Hampton 1983), glucose-dependent insulinotropic polypeptide (GIP) (Morgan et al. 1978) and aMT6 s (Arendt et al. 1985, modified as described by Aldhous \& Arendt 1988) were all measured using in-house RIAs. The interassay coefficients of variation were less than $10 \%$ for these assays. For all analyses, samples obtained from a single subject were measured in the same assay.

\section{Statistical analysis}

Urine aMT6s data underwent a computerised cosinor analysis, using a program developed by Dr D S Minors at the University of Manchester. All other data obtained were subjected to repeated measures ANOVA (two factor: day of study, time) using the SuperAnova package (Abacus Concepts Inc., Berkeley, CA, USA). The data for individual time points were then compared between the 3 days using a one-way ANOVA followed by Duncan's new multiple ranges test to locate individual differences.

\section{Results}

The effectiveness of the phase-shifting protocol was illustrated using the aMT6s data. The mean melatonin acrophase (peak) times are shown in Fig. 2. From these data, it can be concluded that an $8 \mathrm{~h}$ phase-advance shift

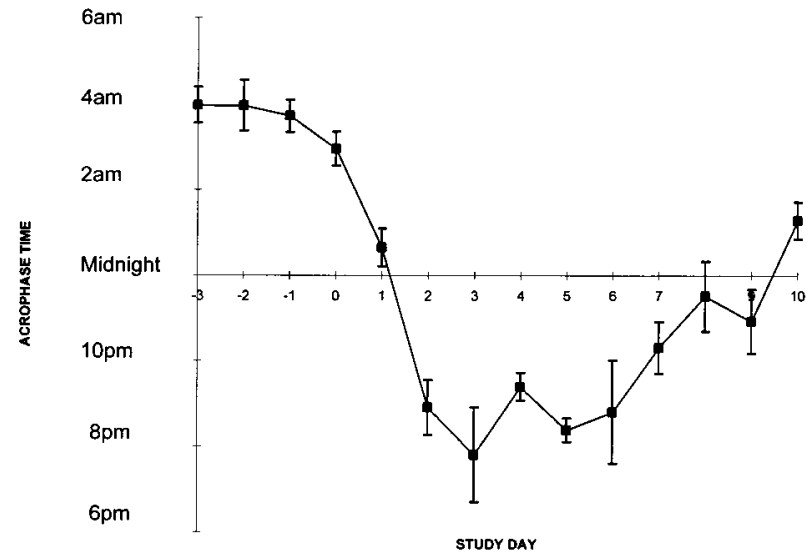

Figure 2 The effectiveness of the phase-shifting protocol is illustrated using the mean \pm S.E.M. aMT6s acrophase (calculated peak) times obtained from the aMT6s data.

was induced by day 6 , with the mean acrophase time moving from approximately $0350 \mathrm{~h}$ (during the baseline period) to $1950 \mathrm{~h}$ at the point of greatest shift. On day 8 , the mean melatonin acrophase time had altered to $2330 \mathrm{~h}$, indicating that the body clock had shifted approximately half-way back to the baseline position.

No statistically significant differences were observed between pre-phase shift, immediate and 2-day post-phase shift basal levels or postprandial responses when the data for insulin, glucose, C-peptide, proinsulin and GIP were considered. Basal and postprandial responses for plasma insulin and glucose on each of the 3 test meal study days are illustrated in Fig. 3.

Basal and postprandial responses for plasma NEFAs on each of the 3 test meal study days are illustrated in Fig. 4. Significantly lower NEFA levels $(P<0 \cdot 05)$ were found immediately after the phase shift, compared with before and 2 days after for both of the basal samples and the $540 \mathrm{~min}$ postprandial sample. In addition, significantly lower NEFA levels $(P<0 \cdot 05)$ were found immediately after the phase shift, compared with before for the samples taken at 40, 360, 420 and 480 min postprandially.

Basal and postprandial responses for plasma TAG on each of the 3 test meal study days are illustrated in Fig 5 a. No statistically significant differences were found for actual TAG values, although there was a trend towards lower fasting TAG levels immediately after the phase shift. To remove the influence of the variation in basal levels, the data were plotted as a difference from basal level, shown in Fig. 5b. Significantly higher TAG levels $(P<0 \cdot 05)$ were found immediately after the phase shift than both before and 2 days after for samples taken at 240 , 360,480 and $540 \mathrm{~min}$ postprandially. In addition, TAG levels were significantly higher $(P<0 \cdot 05)$ immediately after the phase shift than before for samples taken at 90 , 180,300 and $420 \mathrm{~min}$ postprandially. 


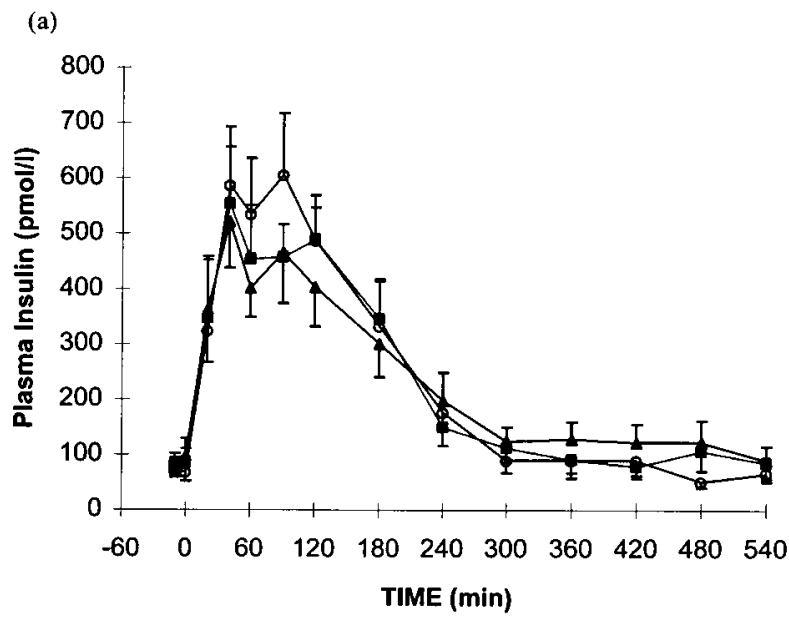

(b)

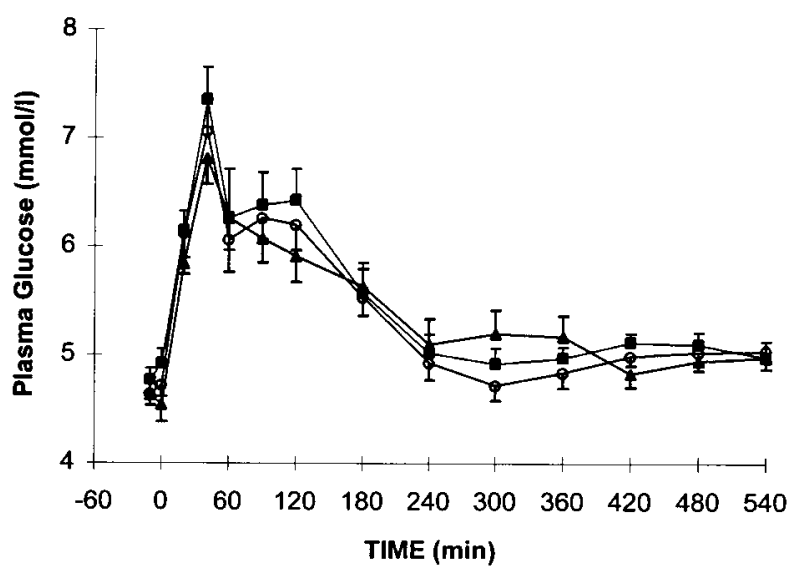

Figure 3 The basal and postprandial responses for plasma insulin (a) and glucose (b) on each of the 3 test meal study days are illustrated. $\mathbf{\square}$, Day $0 ; \boldsymbol{\Delta}$, day $6 ; \bigcirc$, day 8 . Results are means \pm S.E.M. No statistically significant day of study effect was found.

\section{Discussion}

In this study, a previously described combination of appropriately timed bright light and darkness/sleep was successfully employed to phase-advance subjects by approximately $8 \mathrm{~h}$ in a controlled fashion, so that their body clock time was $2130 \mathrm{~h}$ at a clock time of $1330 \mathrm{~h}$, when the test meal was given. Hence, the timing of the meals simulated a body clock time of lunch time (day 0 ) and late evening (day 6). The body clock time on the third meal study day (day 8 ) was approximately $4.5 \mathrm{~h}$ later when compared with the baseline meal study day (i.e. subjects had the test meal at a body clock time of approximately $1800 \mathrm{~h})$.

Insulin sensitivity is known to be lower during the night than in the day (Van Cauter et al. 1992, Lee et al. 1992,

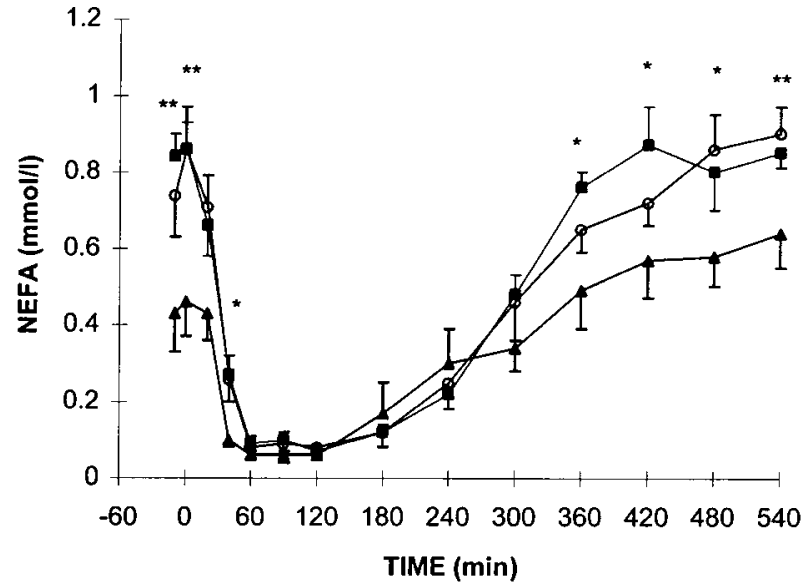

Figure 4 The basal and postprandial responses for plasma NEFAs on each of the 3 test meal study days are illustrated. $\mathbf{\square}$, Day 0;

$\boldsymbol{\Lambda}$, day $6 ; \bigcirc$, day 8 . Statistically significant differences $(P<0 \cdot 05)$ between immediate post-phase shift and pre-phase shift are marked by ${ }^{*}$, and those between immediate post-phase shift and both pre-phase shift and 2-day post-phase shift are marked by **.

Owens et al. 1996), so it might be expected that it would take a greater amount of insulin to cope with the same amount of glucose when the body clock time was $2130 \mathrm{~h}$ (i.e. immediately after the phase shift) than when the body clock time was $1330 \mathrm{~h}$ (i.e. before the phase shift). Indeed, exactly this situation has been found in this laboratory previously (Hampton et al. 1996), when a high-fat premeal was employed. However, in this most recent study, no differences in either the glucose or insulin responses to the test meal were observed when pre- and post-phase shift results were compared. This suggests that a highcarbohydrate pre-meal eliminates the effect of the diurnal rhythm of glucose tolerance. It has been reported previously that both postprandial glucose and lipid tolerance can be influenced by the nutrient composition of the previous meal (Service et al. 1983, Frape et al. 1997). One factor in need of consideration is the time elapsed since the previous sleep, which was considerably greater on the test meal study day immediately after the phase shift than either of the other two. However, sleep deprivation of $10 \mathrm{~h}$ has been reported to have no effect on glucose tolerance (Van Helder et al. 1964).

Considerable differences in the NEFA and TAG responses to a standard meal were observed when pre- and post-phase shift results were compared, as both parameters took considerably longer to return to their basal levels after the phase shift. These results were again in contrast with the findings of previous work conducted in this laboratory which utilised a higher-fat pre-meal (Hampton et al. 1996), although this may, at least in part, be due to the longer sampling period employed in this latest study.

Elevated NEFA concentrations have not often been considered as a risk factor for coronary heart disease, 
(a)

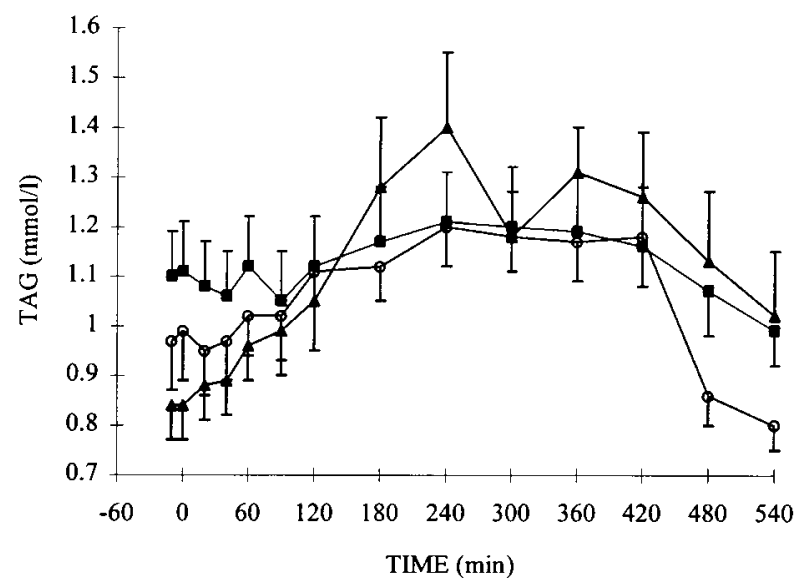

(b)

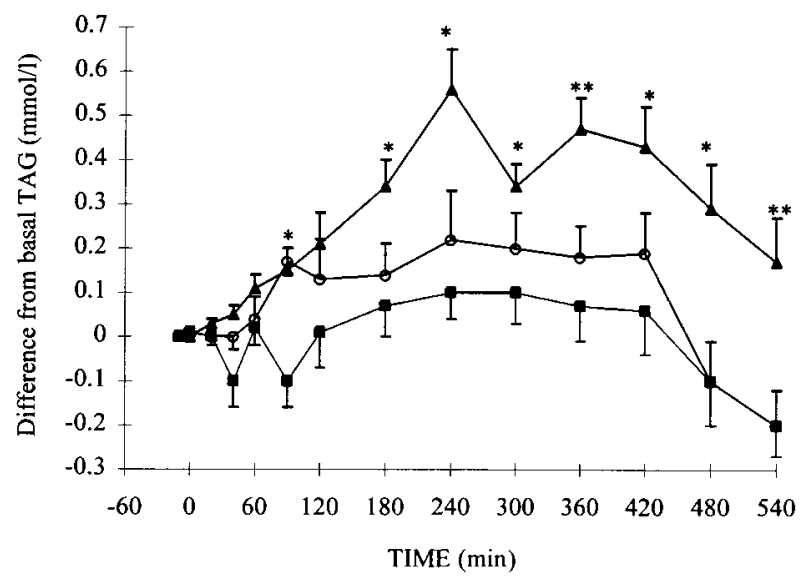

Figure 5 The basal and postprandial responses for plasma TAG (a) on each of the 3 test meal study days are illustrated. No statistically significant differences were found. The basal and postprandial responses for plasma TAG, shown as differences from basal levels (b), on each of the 3 test meal study days are illustrated. Statistically significant differences $(P<0 \cdot 05)$ between immediate post-phase shift and pre-phase shift are marked by *, and those between immediate post-phase shift and both the pre-phase shift and 2-day post-phase shift are marked by **.

$\mathbf{\square}$, Day $0 ; \boldsymbol{\Delta}$, day $6 ; \bigcirc$, day 8 .

probably because plasma NEFA concentrations are often masked by factors such as exercise, smoking and stress level (Frayn et al. 1996). However, in this study, subjects were all non-smokers, their exercise regimes were controlled throughout, and the procedure on each test meal study day was identical, so there would be no reason for a general alteration in the stress levels of the subjects. This is supported by a recent study (Iakovaki 1997), which showed that cannulation had no effect on the basal NEFA levels. Therefore the most likely explanation for the higher fasting NEFA levels observed before the phase shift and
2 days after, compared with immediately after, is the existence of a daily rhythm in plasma NEFA levels. Such a phenomenon has been proposed by other workers (Reaven et al. 1988), who suggested that NEFA levels are highest in the morning and decrease gradually during the day, before there is a gradual increase overnight.

After a carbohydrate-containing meal, hormonesensitive lipase, and hence fat mobilisation, are suppressed by insulin. This is logical as at this time there is no need for the body to mobilise its own fat stores, and the consequent depression of plasma NEFA values is clearly seen on each of the test meal study days. There is unlikely to be a difference in terms of insulin sensitivity because the absolute level of postprandial NEFA suppression and the time to return to basal levels was the same on each test meal study day. This is an important consideration, as elevation of very low density lipoprotein (VLDL)-TAG levels, a known risk factor for coronary heart disease, has been closely related to an impairment in the ability of insulin to suppress circulating NEFAs (McKeigue et al. 1993).

When considering the basal TAG levels, although there were no statistically significant differences, the basal values immediately after the phase shift were considerably lower than before, which could indicate the existence of a diurnal variation in TAG. This was proposed following a recent constant routine study (Morgan et al. 1998), but according to these data, TAG would be expected to be higher during subjective night time rather than lower as found here.

When the postprandial TAG responses are considered, the failure of the TAG levels immediately after the phase shift to return to basal values within $9 \mathrm{~h}$ is consistent with insulin resistance. Insulin activates lipoprotein lipase, a key regulatory enzyme in circulating TAG clearance, and also suppresses VLDL secretion by the liver (Sparks \& Sparks 1993). A lower nocturnal insulin sensitivity could therefore be associated with lower lipoprotein lipase activity and therefore relatively impaired TAG clearance or higher circulating TAG levels of hepatic origin. Although none of the absolute TAG values are particularly high, and thus consistent with our study group being young, non-obese and normolipidaemic, the statistically significant differences illustrated when postprandial responses are shown as differences from basal levels indicates a greater variation from basal levels immediately after the phase shift.

It was interesting to note that the 2-day post-phase shift values were always intermediate (i.e. between the prephase shift and immediate post-phase shift values), suggesting that any effects observed were genuinely due to differences in the internal body clock time when the test meal was eaten. As a consequence of the fact that a high level of TAG is known to be a risk factor for coronary heart disease (Frayn \& Coppack 1992), particularly when found $6 \mathrm{~h}$ after an oral fat load (Patsch et al. 1992) as in this study, and that higher TAG levels have been reported in shift 
workers (Romon et al. 1992), the findings of this study may provide a partial explanation for the increased occurrence of coronary heart disease reported in shift workers.

\section{Acknowledgements}

The authors would like to express their gratitude to the Medical Research Council, the British Heart Foundation and Stockgrand Ltd for their generous support of our work.

\section{References}

Akerstedt T, Knuttsson A, Alfredsson L \& Theorell T 1984 Shift work and cardiovascular disease. Scandinavian Journal of Work and Environmental Health 10 409-414.

Aldhous ME \& Arendt J 1988 Radioimmunoassay for 6-sulphatoxymelatonin in urine using an iodinated tracer. Annals of Clinical Biochemistry 25 298-303.

Arendt J, Bojkowski C, Franey C, Wright J \& Marks V 1985 Immunoassay of 6-hydroxymelatonin sulphate in human plasma and urine: abolition of the urinary 24-hour rhythm with atenolol. Journal of Clinical Endocrinology 60 1166-1173.

Arendt J, Deacon SJ, Morgan LM, Hampton SM, Folkard S, Owens DS \& Ribeiro DCO 1997 Disordered rhythms: strategies for treatment and their relation to pancreatic and metabolic function. In Physiology, Stress and Malnutrition: Functional Correlates, Nutritional Intervention, pp 79-93. Eds JM Kinney \& HN Tucker. Philadelphia: Lippincott-Raven.

Chan OY 1994 Health of female shiftworkers in Singapore. Annals of the Academy of Medicine 23 706-709.

Costa G 1996 The impact of shift and night work on health. Applied Ergonomics 27 9-16.

Deacon S \& Arendt J 1996 Adapting to phase shifts 1. An experimental model for jet lag and shift work. Physiology and Behaviour 59 665-673.

Deacon S, Skene D \& Arendt J 1996 Use of light and/or melatonin in adaptation to phase shifts. In Biological Effects of Light, pp 398-405. Eds MF Holick \& EG Jung. Berlin: De Gruyter.

Ekstrand K, Bostrom PA, Arborelius M, Nilsson JA \& Lindell SE 1996 Cardiovascular risk factors in commercial flight aircrew officers compared with those in the general population. Angiology 47 1089-1094.

Frape DL, Williams NR, Scriven AJ, Palmer CR, O'Sullivan K \& Fletcher RJ 1997 Effects of high- and low-fat meals on the diurnal response of plasma lipid metabolite concentrations in healthy middle-aged volunteers. British Journal of Nutrition 77 375-390.

Frayn KN \& Coppack SW 1992 Insulin resistance, adipose tissue and coronary heart disease. Clinical Science 82 1-8.

Frayn KN, Williams CM \& Arner P 1996 Are increased plasma non-esterified fatty acid concentrations a risk marker for coronary heart disease and other chronic diseases? Clinical Science 90 243-253.

Hampton SM 1983 The C-peptide of proinsulin: its diagnostic use and a possible physiological role. PhD Thesis. University of Surrey.

Hampton SM \& Withey L 1993 Monitoring B cell responses in obese and normal weight subjects; a pilot study. Diabete et Metabolisme 19 $582-585$.

Hampton SM, Beyzavi K, Teale D \& Marks V 1988 A direct assay for proinsulin in plasma and its applications in hypoglycaemia. Clinical Endocrinology 29 9-16.
Hampton SM, Morgan LM, Lawrence N, Anastasiadou T, Norris F, Deacon S, Ribeiro D \& Arendt J 1996 Postprandial hormone and metabolic responses in simulated shift work. Journal of Endocrinology $151259-267$.

Iakovaki M 1997 Is there a diurnal variation in plasma non-esterified fatty acid levels? MSc Thesis. University of Surrey.

Lee A, Ader M, Bray GA \& Bergman RN 1992 Diurnal variation in glucose tolerance: cyclic suppression of insulin action and insulinsecretion in normal-weight, but not obese, subjects. Diabetes $\mathbf{4 1}$ 750-759.

Lennernas M, Akerstedt T \& Hambraeus L 1994 Nocturnal eating and serum cholesterol of three-shift workers. Scandinavian Journal of Work and Environmental Health 20 401-406.

McKeigue PM, Laws A, Chen YD, Marmot MG \& Reaven GM 1993 Relation of plasma triglyceride and apoB levels to insulinmediated suppression of non-esterified fatty acids: a possible explanation for sex differences in lipoprotein pattern. Arteriosclerosis and Thrombosis 13 1187-1192.

Monk TH, Folkard S \& Wedderburn AI 1996 Maintaining safety and high-performance on shiftwork. Applied Ergonomics 27 17-23.

Morgan LM, Morris BA \& Marks V 1978 Radioimmunoassay of gastric inhibitory polypeptide. Annals of Clinical Biochemistry 16 6-14.

Morgan L, Arendt J, Owens D, Folkard S, Hampton S, Deacon S, English J, Ribeiro D \& Taylor K 1998 Effects of the endogenous clock and sleep time on melatonin, insulin, glucose and lipid metabolism. Journal of Endocrinology 157 443-451.

Owens DS, Macdonald I, Benton D, Sytnik N, Tucker P \& Folkard S 1996 A preliminary investigation into individual differences in the circadian variation of meal tolerance: effects on mood and hunger. Chronobiology International 13 435-447.

Patsch JR, Miesenbock G, Hopferwieser T, Muhlberger V, Knapp E, Dunn JK, Gotto AM \& Patsch W 1992 Relation of triglyceridemetabolism and coronary artery disease: studies in the postprandial state. Arteriosclerosis and Thrombosis 12 1336-1345.

Reaven GM, Hollenbeck C, Jeng C-Y, Wu MS \& Chen YD 1988 Measurement of plasma glucose, free fatty acid, lactate, and insulin for $24 \mathrm{~h}$ in patients with NIDDM. Diabetes 37 1020-1024.

Romon M, Nuttens MC \& Fievet C 1992 Increased triglyceride levels in shift workers. American Journal of Medicine 93 259-261.

Service FJ, Hall LD, Westland RE, O'Brien PC, Go VLW, Haymond MW \& Rizza RA 1983 Effects of size, time of day and sequence of meal ingestion on carbohydrate tolerance in normal subjects. Diabetologia 25 316-321.

Smith L \& Folkard S 1993 The perceptions and feelings of shiftworkers' partners. Ergonomics 36 299-305.

Sparks JD \& Sparks CE 1993 Hormonal regulation of lipoprotein assembly and secretion. Current Opinion in Lipidology 34 177-186.

Tuchsen F 1993 Working hours and ischaemic heart disease in Danish men: a 4-year cohort study of hospitalization. International Journal of Epidemiology 22 215-221.

Van Cauter EC, Shapiro ET, Tillil H \& Polonsky KS 1992 Circadian modulation of glucose and insulin response to meals: relationship to cortisol. American Journal of Physiology 262 E467-E475.

Van Helder T, Symons JD \& Radomski MW 1964 Effect of sleep deprivation and exercise on glucose tolerance. Aviation Space and Environmental Medicine 6 487-492.

Received 24 December 1997

Accepted 14 April 1998 